\title{
El arte es una palabra de cuatro patas: simbología y resemantización del perro, animal protagonista en la obra de Wolf Vostell
}

\author{
Marina Bargón García \\ Universidad de Extremadura.
}

\section{RESUMEN:}

En el presente estudio exponemos las conclusiones a las que hemos llegado al analizar pormenorizadamente las obras del artista alemán Wolf Vostell -figura clave en la Historia del Arte de la segunda mitad del siglo XX- en las que podemos encontrar la presencia canina. De este estudio hemos concluido los distintos significados que este animal desprende en el lenguaje vostelliano, ampliando el horizonte y el conocimiento que sobre el artista se tiene, así como apuntado las distintas utilizaciones que de ellos hace en su obra, tanto reconocible como abstracta, en distintos formatos (happenings, conciertos Fluxus, environments, etc.) ${ }^{1}$.

\section{PALABRAS CLAVE:}

Vostell, iconografía, happening, animales, naturaleza

\section{ABSTRACT:}

In the present paper we expose the conclusions about the works of the artist Wolf Vostell - a very important artist of the second half of the 20th century of the History of Art- which we can find the presences of the dogs. We have concluded the different meanings of this animal in the Vostell's language, increasing the knowledge about the artist, as well as showing the different uses of the canine in the works of the German artist, figurative and abstracts, in different formats (happenings, Fluxus concerts, environments, etc.).

KEYWORDS:

Vostell, iconography, happening, animals, nature

\footnotetext{
Este trabajo se enmarca en el Proyecto de Investigación Nacional titulado: Paisajes Culturales en la Extremadura Meridional: una visión desde el Patrimonio (HAR2017-87225- P), financiado por el Ministerio de Ciencia, Innovación y Universidades del Gobierno de España, Agencia Estatal de Investigación y Fondos FEDER, coordinado por Vicente Méndez Hernán y Moisés Bazán de Huerta. Así mismo, este trabajo deriva de la tesis doctoral: BARGÓN GARCÍA, Marina, Del mundo mineral al mundo animal. Wolf Vostell y la utilización de la naturaleza en obras de arte intermedia, Departamento de Arte y Ciencias del Territorio, Universidad de Extremadura, Cáceres, 2019.
} 
"Podemos juzgar el corazón de un hombre según como trata a los animales”

Inmanuel Kant

“El tiempo vendrá en el que los hombres miren a los asesinos de animales como hoy miran a los asesinos de hombres"

Leonardo da Vinci

\section{De perros, hombres y artes}

La historia de los perros está ligada a la de los humanos que habitaban Europa del Este hace 12.000 años, quienes estaban rodeados de lobos. Habiendo aprendido a cazar y a recolectar, los lobos se dieron cuenta de que estos humanos depositaban los desperdicios de la carne consumida en los límites de su agrupación comunitaria. De esta manera, la manada de lobos fue acercándose poco a poco a la especie humana. Los humanos siguieron depositando los restos alimenticios porque los lobos habían comenzado a proteger a sus hijos, sus terrenos, su ganado, etc. Es decir, habían comenzado a entenderlos como parte de su manada. Pasado el tiempo, la manada de lobos dependía totalmente de los humanos para su subsistencia y por ello los acompañó a donde quiera que estos fueran. Perdieron muchos de sus hábitos, de su instinto y comenzaron a ser más dóciles ${ }^{1}$.

El perro es considerado el mejor amigo del hombre porque lleva milenios entre nosotros, estando su genética predispuesta al ser humano (como alteración evolutiva). Las diferentes razas de perros han sido creadas por la transmutación de la especie al medio y a los seres humanos (existiendo más de 300 razas). ${ }^{2}$

Sin embargo, en todas las culturas el perro es considerado como un psicopompo (principalmente el perro negro). Desde Anubis, quien ocasionalmente es representado como un perro negro que acompaña a Isis, a Cerbero, Thot, Hécate o Hermes, las culturas antiguas muestran cómo el perro ayuda a los difuntos a cruzar al otro lado, visita los infiernos y, además, los vigila. El perro es guía, también, en los trances funestos (en algunas culturas, como las andinas

PARKER, Heidi, "Genomic analyses of modern dog breeds", Mammalian Genome, vol. 23, n. 1 y 2, 2012, pp. 21- 22.

2 PlayGround. Consultado el 10/07/2017. y mejicanas, eran sacrificados para que guiaran el alma de su difunto dueño). ${ }^{3}$

Este animal ha sido representado en la historia del arte como un ser que ejemplifica la ambivalencia. Por un lado, el perro ha sido mostrado como héroe de la civilización, como un antepasado mítico de los hombres, como icono de la potencia sexual (y por tanto de la fertilidad) y como símbolo de la vitalidad desbordante "como la naturaleza en primavera". Por otro, ha sido denostado en algunas religiones como la musulmana, donde se le ve como símbolo del mal y la impureza (aunque aquel que maltrate a un perro será maldecido). Esta dualidad entre el bien y el mal es más representativa en el Extremo Oriente, donde el perro es el fiel compañero del hombre, mientras que si aparece representado como lobo o chacal se entenderá que es impuro y despreciable.

En la cultura occidental el perro ha sido representado desde el principio como fiel compañero. Desde las pinturas rupestres a la cultura grecorromana (donde aquel que maltratase a una galgo corría la misma suerte que la infringida a ese animal), las escenas de cacería medievales, los retratos renacentistas y barrocos, el género costumbrista y el de paisaje, así como las obras de vanguardia y posterior arte contemporáneo e intermedia, hasta nuestros días, el perro ha sido representado en todos y cada uno de los apartados artísticos (mostrando las significaciones anteriormente expuestas, principalmente la sexual) ${ }^{5}$.

Relativo al siglo XX, encontramos que el perro y los animales vivos son recurrentes en las propuestas de distintos periodos artísticos: desde las vanguardias, donde -por ejemploel cineasta Luis Buñuel refleja el concepto de moralidad surrealista en su película Un perro andaluz (1929), hasta otros artistas posteriores, quienes han utilizado los animales como propuesta de reflexión. Pier Paolo Calzolari utilizó

3 CIRLOT, James, Diccionario de los símbolos, 2 Edición, Editorial Labor, Barcelona, 1992, p. 365.

4 CHEVALLIER, Jean, Diccionario de los símbolos, Editorial Herder, Barcelona, 1986, p. 820.

5 El proyecto "Google Art \& Culture" ha recogido una muestra de diez obras de arte en representación de la iconografía y aceptación que los perros han tenido en diferentes soportes artísticos para el público a lo largo de la Historia del Arte, pasando por Lavinia Fontana, Gustave Courbert, Paul Gauguin, Paul Klee, Diego Rivera o Jeff Koons, por ejemplo. https://www.google. com/culturalinstitute/beta/theme/mQKC2nfIYw30Jg. Consultado el 22.07.2017. 
a los canes en obras suyas como Malina (1967), La casa ideale (1967) o Il giardino dei Getsemani (1979), donde expone a los perros confrontados a diversos objetos, muy relacionado con lo practicado por Jannis Kounellis en algunas de sus obras, como en Doce caballos vivos (1969) o Sin Título 1967 (1979)6. También William Wegman realizó acciones con su propio perro -Man Ray- para posteriormente trabajar con otros sabuesos vivos y reflexionar sobre la sociedad de consumo, la soledad y la imagen edulcorada de la realidad, en obras como Bikini (1999) o Catty (2000) ${ }^{7}$. Acciones de corte ritual son también realizadas por otros artistas, como por ejemplo Joseph Beuys en su obra Me gusta América y yo le gusto a América (1974), quien reflexiona sobre el espacio, los indios americanos (reflejados en la presencia del coyote americano por antonomasia) y la experiencia, ya que, según el artista, "todo conocimiento humano parte del arte" ${ }^{8}$. También Miquel Barceló -en una de sus primeras obras realizada para la Documenta de Kassel en 1982 - utiliza la figura del perro en su obra Persecución nocturna en la periferia de la ciudad. Lo plasma en un escorzo, inmerso en un paisaje y centrando toda la importancia de la escena en el can, como uno de sus autorretratos metamorfoseados que versan sobre la Historia del arte 9 . Para terminar, referenciaremos a otro creador que también recurre a la figura de los perros en sus obras: el artista pop Keith Haring, quien -en su primera etapareflexiona sobre las situaciones absurdas a las que nos enfrentamos en el presente, pasado y futuro, personificados en su perro y representados con su particular estética, como en sus obras Sin título (1980) o Sin título (1982) ${ }^{10}$.

6 Tal y como se expone en la tesis de CORTÉS ZULUETA, Concepción, Fundamentos biológicos de la creación: Animales en el arte $y$ arte animal, Departamento de Historia y Teoría del Arte, Universidad Autónoma de Madrid, Madrid, 2016, p. 112.

7 SIMON, Joan; WEGMAN, William, William Wegman: Funney/Strange, Yale University Press, New Haven, 2006, p. 3.

8 IERARDO Esteban, "La liebre y el coyote; encuentros con lo animal y lo secreto en la obra de Joseph Beuys", recuperado de http://www. temakel.com/presentacionierardo.htm, 2005.

9 RUI DE MARTíN, María del Carmen, "Las exposiciones de Miquel Barceló en París", Cerámica= Keramos: revista trimestral del arte y ciencia de la cerámica, vol. 141, 2016, pp. 43- 44.

10 KOLOSSA, Alexandra; HARING, Keith, Haring, Taschen, Los Ángeles, 2004, pp. 7, 8, 16, 33.
2. Wolf Vostell: artista germano-español y amante de los animales

Wolf Vostell (1932 Leverkusen - 1998 Berlín) fue un artista nacido en Alemania profundamente marcado por su historia más reciente. Siendo niño tuvo que huir con su familia a Checoslovaquia ante la amenaza nazi, regresando al acabar la guerra a Colonia. Derivado de estas experiencias Vostell desarrolló su faceta artística como grito en favor de los más desfavorecidos y agraviados por tragedias como el Holocausto, para defender a todas aquellas vidas que, en algún momento, son injustamente tratadas por la sociedad que el ser humano ha creado. Wolf Vostell (co-creador del happening, inventor del video-arte, miembro fundador de Fluxus, etc.) entendió que, en muchas circunstancias, los animales también habían sufrido las injusticias del hombre y que podía aprenderse más de ellos que de muchas nuevas tecnologías que, en principio, facilitan y enriquecen nuestra vida.

Vostell siempre fue un amante de los animales. Su mujer (Mercedes Guardado, una extremeña que refuerza el amor del artista por España y Extremadura) cuenta cómo se hicieron con un galgo, ya que Vostell lo deseaba más

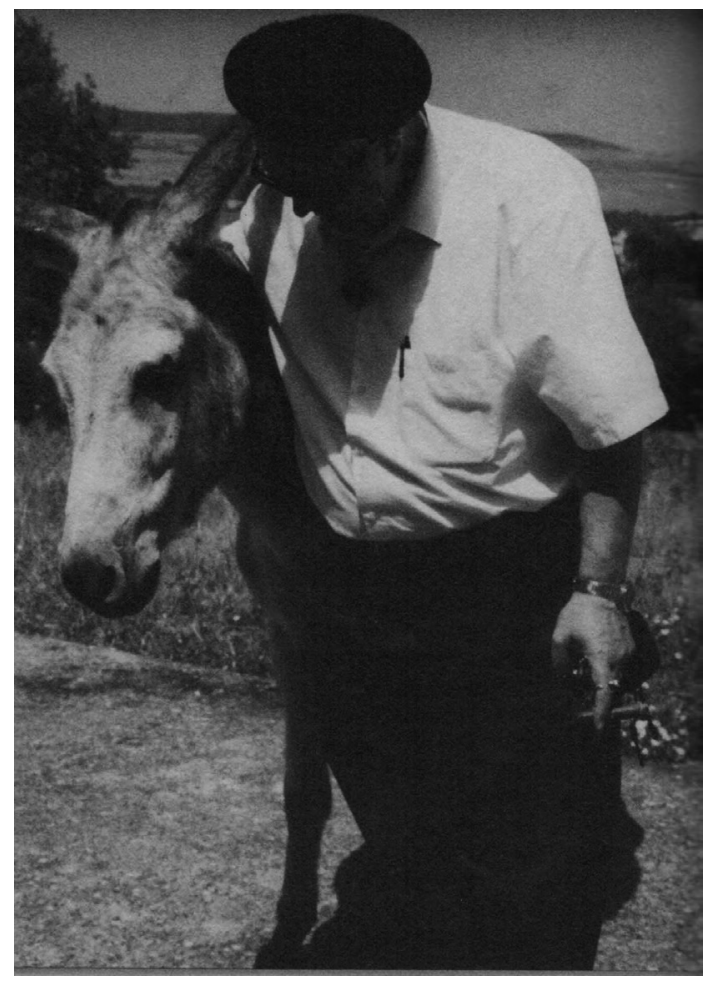

Fig. 1. Wolf Vostell y su burro Leonardo. Cortesía Archivo Happening Vostell y Junta de Extremadura. 
que ningún otro miembro de la familia, al que llamaron Nugaima, y lo llevaron alguna vez a un club de perros para que corriera detrás de una liebre eléctrica ${ }^{11}$. Posteriormente tuvieron otros dos perros: Vela (en honor a Velázquez) y Tizi (en honor a Tiziano), de los que nacieron Paz y Wolf. También tuvieron dos gatos llamados Piqui (por Picasso) y Miró, además de las tortugas Salomón y Saba y del burro Leonardo. Burros tuvieron otros tres: Platero, Happening y Fluxus ${ }^{12}$. Por lo tanto, comprobamos que Vostell conocía el mundo animal de primera mano y que, además, disfrutaba con su compañía. Todos estos animales son importantes en su obra, ya que adquieren una profusa representación y una fuerte conceptualización.

Sus propios perros participaron en alguna de sus obras, ayudados por supuesto por el artista, y así es como comenzaremos la esquematización en apartados de sus obras en relación a los canes.

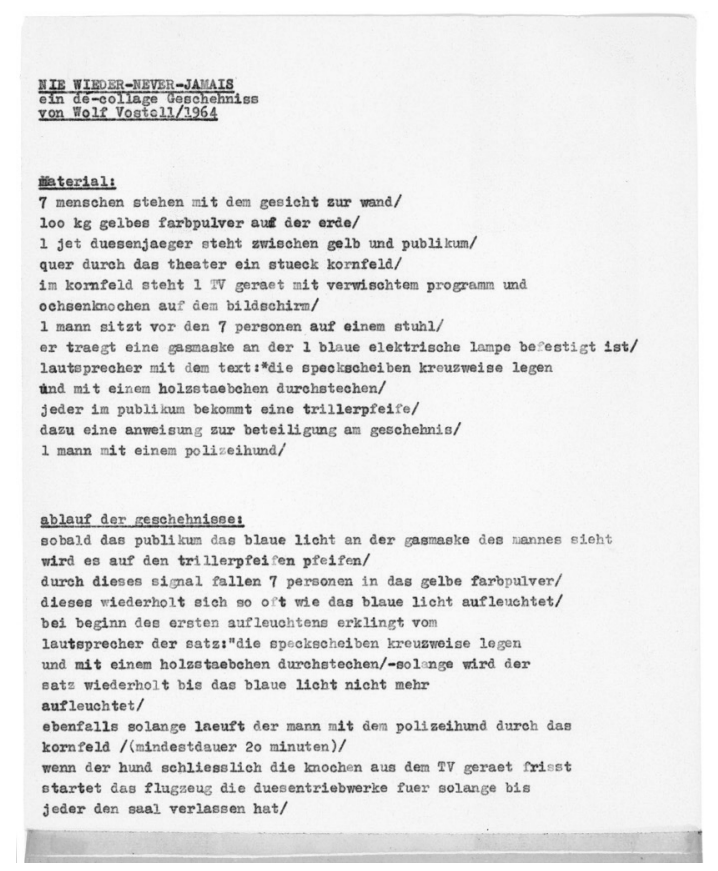

Fig. 2. Happening Nunca más-Jamás jamás (1964). Cortesía Archivo Happening Vostell y Junta de Extremadura.

\section{Categorización de los perros en la obra de} Wolf Vostell

Derivado de este estudio hemos encontrado que la representación canina en el arte vostelliano se dispone según la siguiente categorización:

\section{Representación figurativa}

a. Vivo

I. Actuando con ayuda

II. Actuando por sí mismo

b. Muerto

2. Representación abstracta

Representación figurativa:

\section{PERRO VIVO}

En primer lugar, deberemos hablar de aquellas obras en las que el animal se encuentra en un estado reconocible (figurativo) y vivo. Dentro de esta categoría cabe discernir entre las obras en las que el perro interactúa con/para la obra por sí mismo y aquellas en las que necesita la ayuda de una persona (el artista).

\section{Actuando con ayuda}

Comenzando por esta última, apuntamos que generalmente se trata de las diferentes versiones que Vostell realiza del concierto Siberia Extremeña. La zona conocida como Siberia Extremeña responde a una zona geográfica dentro de la Comunidad Autónoma de Extremadura. Es así llamada desde - probablemente- el siglo XVIII, estando documentada con este nombre por José Ramón Mélida, quien así denomina a este espacio por primera vez $^{13}$. Esta zona de la provincia de Badajoz, de casi remoto acceso hasta mediados del siglo XX, delimita al Este con Castilla-La Mancha, al sur con La Serena, al Oeste con las Vegas Altas y al Norte con la provincia de Cáceres. El paisaje siberiano supone una suerte de serranías con volumetrías agrestes y escarpadas (estribaciones de los Montes de Toledo), con cinco pantanos y amplios espacios cuya ma-

\footnotetext{
13 MÉLIDA ALINARI, José Ramón, Catálogo Monumental de España. Provincia de Badajoz (1907-1910), Ministerio de Instrucción pública y Bellas Artes, Madrid, 1925, pp. $62-68$.
} 
yor característica (de septiembre a diciembre, debido a la falta de lluvias) es la aridez. Sin embargo, pese a que su paisaje recuerde a lo denominado como "Extremadura profunda" es una tierra fascinante, que ha vivido en sus entrañas el peso de la Historia, rodeada de agua, vegetación y vida ${ }^{14}$. El folclore tradicional no se vio interrumpido con la llegada del Plan Badajoz (y con él el progreso, la economía y el trabajo). Sin embargo, en sus raíces lleva el peso de las injusticias vividas en aquellas tierras, el hambre y la miseria, la marca de la Guerra Civil, de los represaliados y de los huidos, pareciendo estar representadas estas características en sus paisajes agrestes y abruptos, solitarios, imponentes ${ }^{15}$. Estas peculiares características son las que interesaron a Vostell de especial manera en su visita a La Siberia en julio de $1981^{16}$ y es lo que representará en sus diferentes variaciones del concierto fluxus Siberia Extremeña ${ }^{17}$ (además de en los siete

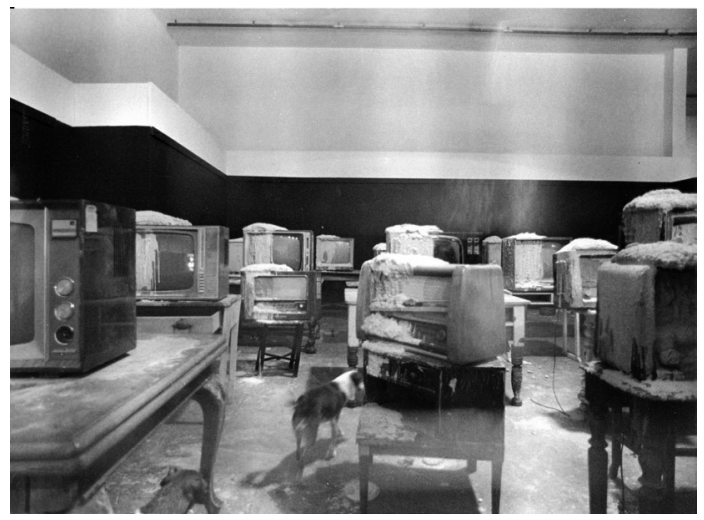

Fig. 3. Environment Depresión Endógena (1988/9). Cortesía Archivo Happening Vostell y Junta de Extremadura.

14 Picachus Proyect Videoart Film, en manos de Pablo Ruiz Sánchez, realiza un video promocional de la zona en el que fragmenta, divide, duplica, triplica y manipula el paisaje, interrumpido sólo por cuatro conceptos fundamentales. En el desarrollo del vídeo se puede ver cómo las características principales son vegetación, agua (bien líquida o en forma de nube), camino (en coche o en barco) y paisaje. https://www.youtube.com/ watch?v=NNFKGrzxkyE Consultado el 21.8.2018,

15 CAMACHO CABELLO, José, "La Siberia extremeña: Marco geográfico y desarrollo histórico”, Revista de Estudios Extremeños, vol. 55, n. 3,1995, p. 967.

16 CORTÉS MORILLO, Josefa, "Wolf Vostell, Juan José Narbón y Extremadura", Norba, Revista de Arte, n ${ }^{\circ}$. XXV, 2005, p. 280.

17 GUASCH, Anna Maria, "Ex(h)ibir el Fluxus (19951962)", Simposio Happening, Fluxus y Otros comportamientos artísticos de la segunda mitad del siglo XX, Editoria Regional de Extremadura, Mérida, 2001, p.44. cuadros y diversos dibujos que hizo sobre esta temática).

La primera de ellas la realiza en 1982, en el Museo Vostell Malpartida, como parte integrante de las acciones que allí se desarrollaron durante 24 horas para celebrar el cumpleaños del artista. El concierto fluxus comenzó con Vostell, acompañado de uno de sus perros, Velázquez ${ }^{18}$. Ambos tocaron juntos el piano (el perro con la ayuda del artista), libremente, mientras Ulrike Ottinger (artista cinematógrafa $\mathrm{y}$ fotógrafa alemana ${ }^{19}$ ) depositaba encima de las teclas, una por una, ramas que se encontraban en un carro tirado por mulas. Esta misma acción fue repetida en Calais el mismo años, donde la variación animalística, en este caso, vino de la participación de un perro llamado $\mathrm{Ida}^{20}$. De igual manera sucede en otro de sus conciertos, El Grito (1990), realizado en la Sala Polivalente de París. En ella dispuso Vostell un piano de cola donde tocaría, de igual manera, con el buldog de unos amigos, llamado Enoch. Según analiza Ana María Valdellós Sedeño, el concierto transcurrió de la suma de:

"grandes masas vibratorias ... donde emplea irónicamente la "Sinfonía de los Mil" de Gustav Mahler con dos cuartetos de cuerda, cuatro leñadores, una orquesta femenina, zambombas, un piano, veinte televisores, cinco sopranos, un coro de treinta voces, treinta aspiradores, trombones, oboes y un coche accidentado para terminar con una acumulación de fuentes sonoras" 21 .

Valdellós Sedeño resalta, también, de estas creaciones la interactuación con el piano, lo que supone una desvinculación directa con el mundo de la tradición en arte (y es por ello que localiza sus actuaciones en ambientes como, por ejemplo, el MVM, al aire libre, liberándolo de cualquier salón decimonónico burgués), y lo entierra -bien con ramas o bien con un hormigonado-, convirtiéndolo en un elemento toté-

18 GUARDADO OLIVENZA, Mercedes, Mi vida con Vostell. opus cit., p. 309.

19 Wolf Vostell y Ulrike Ottinger mantuvieron una estrecha relación, llegando a aparecer el artista alemán en una cinta de Ottinger, Ticket of No Return de 1969 (la persona que aparece en la mesa). FRIEDEN, Sandra, Gender and German Cinema: Feminist Interventions, Oxford, 1993, pp. 192- 193.

20 GUARDADO OLIVENZA, Mercedes, Mi vida con Vostell. opus cit., p. 315.

${ }^{21}$ SEDEÑO VALDELLÓS, Ana María, "Wolf Vostell: la vida como ruido", Sinfonía Virtual. Revista de Música clásica y reflexión musical, nº. 1, 2006, p. 15. 
mico directamente relacionado con los object trouvé duchampianos ${ }^{22}$.

Sin embargo, esta desvinculación con la tradición no es total, sino selectiva. En las variaciones de sus conciertos fluxus Siberia Extremeña recurre a otro tipo de materiales o instrumentos folclóricos, como cantos o zambombas, así como también confronta la tecnología rural con la tecnología novedosa, como la televisión o una banda magnética. La implicación canina en estos conciertos está, también, vinculada al mismo mensaje: a un perro no se le puede pedir que no desafine, únicamente podemos agradecerle el esfuerzo y esperar que no miccione en las teclas.

También existe un dicho italiano que resalta que cuando a alguien no se le da bien hacer algo lo hace come un cane al pianoforte -como un perro tocando el piano-. Se sobrentiende que el animal lo hará mal porque no está dentro de sus habilidades ni de sus instintos el saber o poder tocar el piano.

Por tanto, encontramos que en las acciones que realizaron los perros intervienen tres variantes: la primera es el azar, puesto que los canes podían haberse comportado de manera completamente imprevisible. La segunda es la colaboración ya que, sin la ayuda de Vostell, habría sido más difícil que los animales interactuaran con el instrumento por libre decisión. Y la tercera es la creación artística en sus acciones, asumiendo que lo realizado por las manos del artista y las patitas del perro en ese preciso instante es arte porque la vida, en sí misma, lo es (retornando así al dogma vostelliano $\mathrm{Vi}$ $d a=$ Arte, Arte $=$ Vida .

\section{Actuando por sí mismo}

Otra de las categorías donde encontraremos a este animal será aquella que nos hable de la interactuación del perro con la obra solo, sin necesidad de ayuda por parte del artista.

Es el caso de la idea que Vostell tenía para el desarrollo de su happening Nunca más- Jamás Jamás (1964):

"Desarrollo de la acción: ... o mientras que el hombre con el perro policía esté andando por el campo de trigo/ cuando el perro comience a

22 SEDEÑO VALDELLÓS, Ana María, "Wolf Vostell: la vida como ruido", opus cit., p. 16.

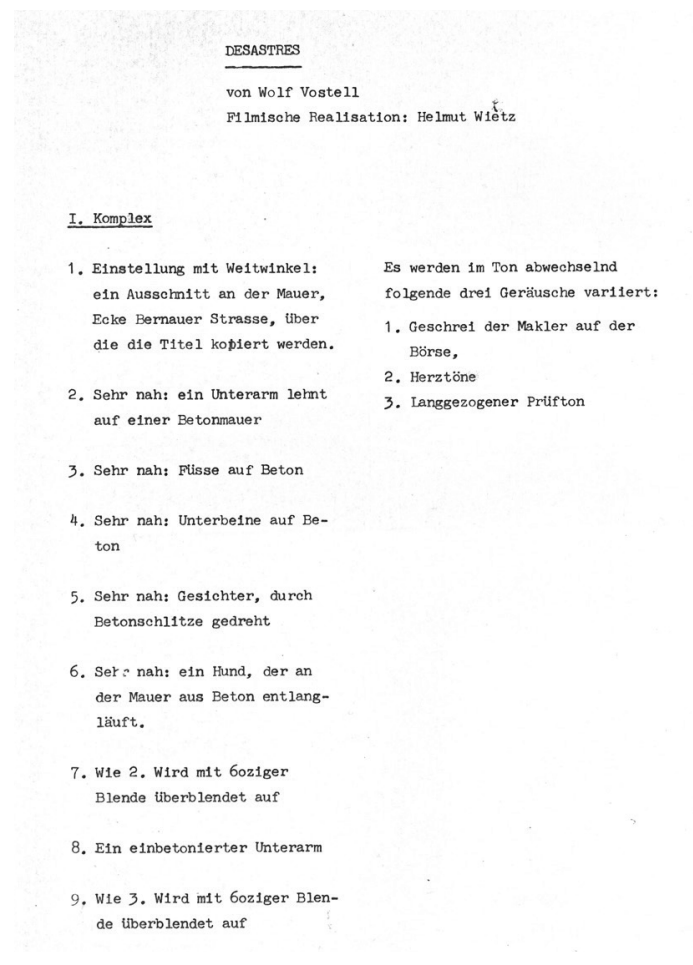

Fig. 4. Film Desastres (1972). Cortesía Archivo Happening Vostell y Junta de Extremadura.

comerse los huesos del televisor el avión pondrá en marcha el reactor"23.

Lo importante es que parece que esta acción no llegó a realizarse finalmente (al no encontrar documentación gráfica o visual que lo avale), sino que la idea del artista era someter al perro a un acto azaroso e instintivo, para el desarrollo de la obra. Se trata de un proceso en el que la vida misma juega su papel, confrontando el acto creativo vital con el azar.

De igual manera debemos entender la participación de estos animales en las diferentes versiones de su obra Depresión Endógena, ambientes en los que el artista enfrentaba elementos tecnológicos, como radios y televisores, con organismos vivos, como pavos, perros, patos, etc. De esta manera, pretendía el artista, poner en evidencia la estupidez del hombre anulado por la información. La primera vez que utiliza a los canes en estos environments es en 1978, en la retrospectiva que le organizaron la Fundación Gulbenkian y la Galería de Belem, en Lisboa. Para ello contrapuso la imagen de ocho perros con las de los televisores, espacio en el

23 VV.AA., El teatro está en la calle. Los Happenings de WOLF VOSTELL, Apéndice en Castellano del Catálogo, Consorcio Museo Vostell Malpartida, Mérida, 2010, p. 10. 


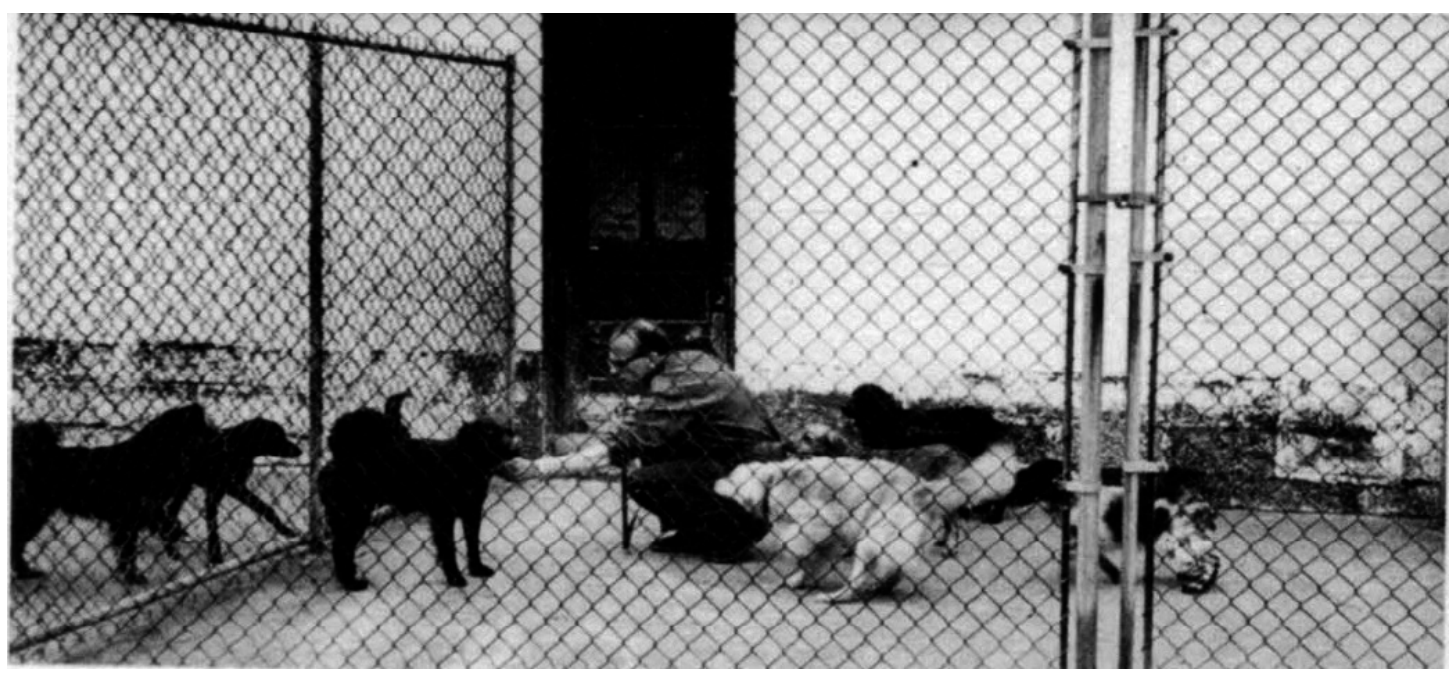

Fig. 5. Happening Perros y chinos no son admitidos (1966). Cortesía Archivo Happening Vostell y Junta de Extremadura.

que, además, nacieron otros dos perros más. De igual manera hizo la versión de 1979 para la exposición Fluxus en el I'E.L.A.C., Lyon, donde juntó cinco perros en el mismo espacio expositivo, delimitado por una jaula donde estaban los animales y una mesa hecha de pan que sostenía los televisores ${ }^{24}$. En otra versión realizada en 1979, en el Museo Nacional Soares de Reis, Oporto ${ }^{25}$, los perros -en este caso dos- y los televisores estuvieron dispuestos en un jardín.

En ningún momento le interesó al artista que la idea que se tuviese de los televisores fuera negativa, tal y como opina Mercader "es absurdo que la gente tire a la basura los televisores viejos. Estos televisores han estado educándolos durante diez años o más, han conformado su sistema nervioso" ${ }^{26}$. El contraste entre animales y tecnologías, de lo natural con lo artificial $^{27}$, en el espacio artístico queda perfectamente definido en palabras de Sagrario Aznar:

"Estamos viendo, pues un atípico "gabinete de curiosidades", pero también estamos viendo un lugar caótico, un cementerio de vestigios

24 GUARDADO OLIVENZA, Mercedes, Mi vida con Vostell. opus cit., p. 272.

25 El estudio de estos environments en las dos sedes portuguesas ha sido llevado a cabo por María del Mar Lozano Bartolozzi en su conferencia Artistas Portugueses en el Museo Vostell Malpartida (MVM)(Extremadura-España). Documentación del Archivo Happening Vostell (AHV).

26 MERCADER I CAPELLÀ, Antoni, "Mitjans Tecnològics Que Provoquen i Aboquen?”, Revista de Recerca $i$ d'anàlisi [Abans Treballs de Comunicació], n.17, 2002, p. 46.

27 BORDINI, Silvia, Videoarte \&t Arte: Tracce per Una Storia, Lithos editrice, Roma, 1995, p. 35. tecnológicos en el que toda comunicación es imposible, un lugar, entonces, de pérdida de la memoria colectiva, al contraponer dos modelos, el orgánico y el mecánico. Depresión endógena se convierte en un espacio fascinante y contradictorio, en el que unos animales cautivos se hallan inmersos en un espacio de culturización. Se trata, es evidente, de no abdicar frente a las mitologías tecnológicas, sino de enfrentarse a ellas motivando el pensamiento individual a todos los niveles y, en consecuencia inmediata, estimulando la conciencia colectiva"28.

Igualmente, en el film-happening Desastres (1972) comenzaba con la imagen del Muro de Berlín y, poco a poco, se sucedían las imágenes que en la mente de Vostell habían sido concebidas o las obtenidas para la reproducción de la cinta: "SECUENCIA: 6. Muy cerca: un perro andando por el muro de hormigón." ${ }^{29}$

Por lo tanto, también podemos hablar de estos animales y esta obra en relación con el azar, puesto que el acto de grabar al perro no puede ser dirigido, sino que únicamente puede ser pensado y después grabado según el perro actúe (¿y si decide correr asustado? ¿o quedarse quieto moviendo el rabo?). Se trata, en vez del teatro sintético del que habló Gino di Maggio, de la cinta sintética: "La revolución futurista es una revolución global, afronta el problema del arte total, y con el teatro sintético anticipa

${ }_{28}$ AZNAR ALMAZAN, Sagrario, "El Vídeo, en el límite entre el arte y la tecnología. Las videoinstalaciones", Espacio, Tiempo y Forma, Historia del Arte, n.8, 1995, p. 307.

29 VV.AA., El teatro está en la calle Los Happenings de Wolf Vostell, opus cit., p. 41. 
de algún modo el concepto de evento. Uno de los eventos era un perro que atravesaba el escenario" 30 .

Con todo, nos corresponde relacionar esta categoría con el que, quizás, sea su happening más complejo y en el que los perros juegan un papel fundamental. Se trata de Prohibidos perros y chinos o el descubrimiento de lo que significa el medio ambiente (1966) ${ }^{31}$, realizado en Nueva York. Este happening refleja uno de los pasajes más dolorosos en la historia del pueblo chino. En el parque público Huangpu Park -en el centro de China, construido al estilo europeo para atraer a la comunidad extranjera- existía una plaza que prohibía expresamente la entrada a perros y a chinos: "Los Jardines están reservados para la Comunidad Extranjera... Perros y bicicletas no son admitidos". Lo cierto es que, hoy en día, supone un icono de las muchas humillaciones que sufrió el pueblo chino por parte de los países extranjeros (principalmente Inglaterra y Estados Unidos).

Este happening fue pensado para diferentes localizaciones y distintos tiempos. Una de las acciones se sitúa en la perrera de Long Island, donde debían desarrollarse las acciones planeadas en círculos conformados por los asistentes, quienes giraban en direcciones contradictorias. Vostell planeó para el Círculo 3 lo siguiente: "círculo III: las personas del círculo III van en dirección contraria a las del círculo II en dos puntos de los círculos se hallan de 60 a 80 perros metidos en perreras la acción se modifica cada 7 minutos" 32 .

Para el círculo 1 y 4 el artista concibe otro contacto distinto con el animal. Tal y como el artista expresa en el guion del propio happening "3. círculo I y IV. 7.30-7.37 estar tendido en el suelo LADRAN PERROS. 7.38 -7.44 andar en círculo y proyectar en su (de Vostell) lengua un filme con un proyector portátil $8 \mathrm{~mm}$. sobre la guerra del vietmam LADRAN PERROS"33. Como podemos ver, mientras se realizan acciones y se proyectan imágenes se oyen los la-

30 Centro de Estudios MNCARS. (Arch. M/Q 206 (1)) Conferencia de Gino di Maggio Fluxus y Compañia (reflexiones sobre el movimiento artístico revolucionario en Europa y América), Pág. 4. Consultado el 7.10.95.

31 Este happening ha sido ampliamente estudiado por Agúndez en: AGÚNDEZ GARCíA, José Antonio, 10 Happenings de Wolf Vostell, Editoria Regional de Extremadura, Badajoz, 1999, pp. 263- 288.

32 VV.AA., El teatro está en la calle Los Happenings de Wolf Vostell, opus cit., p. 20.

33 Ibídem.

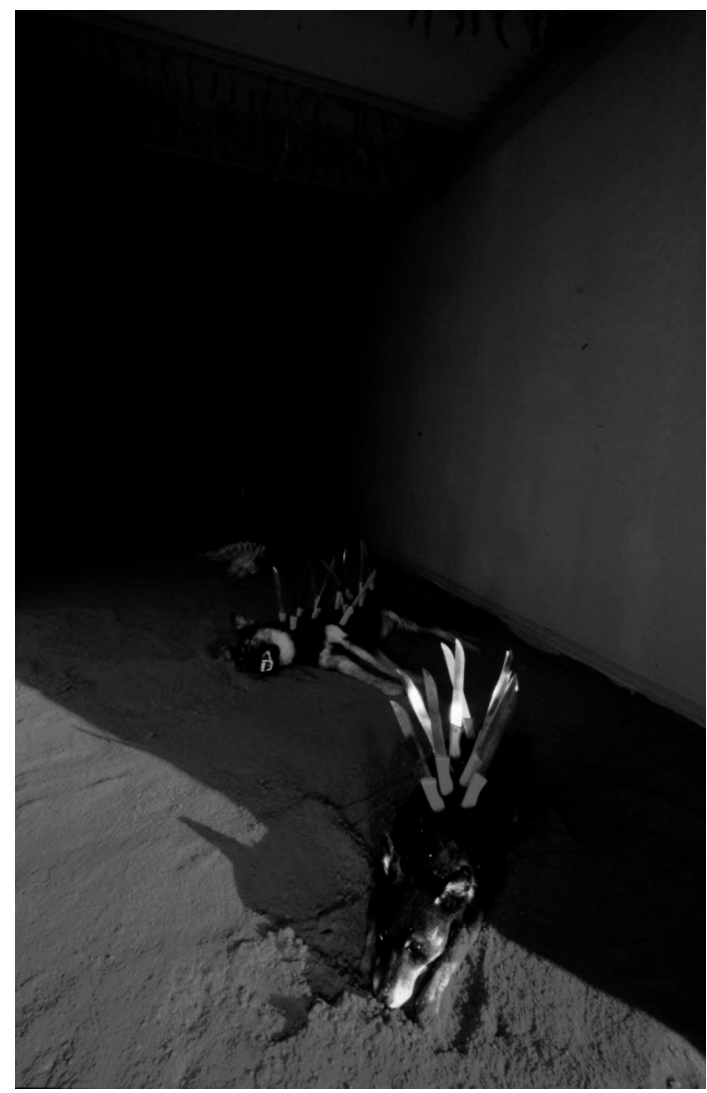

Fig. 6. El tren Fluxus: LOS FUEGOS (1981). Cortesía Archivo Happening Vostell y Junta de Extremadura.

dridos de los perros como banda sonora de la experiencia propuesta por el artista.

Como material usado para el desarrollo del happening también emplea una película de adiestramiento de perros que, suponemos, fue proyectada en algún momento del happening ${ }^{34}$.

En resumen, vemos que la interactuación con el perro (en este happening) se da de tres maneras distintas: la primera es presencial, porque la convivencia entre personas y perros se hace en el mismo espacio (dos círculos en cuyo centro guardan a los perros). La segunda es auditiva, ya que lo que verdaderamente interesa a Vostell de estos animales en el desarrollo de esas acciones son los ladridos que este animal produce. Y la tercera es visual; la película de perros supone una confrontación de imágenes de adiestramiento y disciplina, por lo que la directriz vostelliana nos obliga a llegar al mensaje mediante la visualización de la cinta.

\footnotetext{
VV.AA., Das Theater ist auf der Strasse. Die Happenings von WOLF VOSTELL, Museum Morsbroich, Leverkusen, 2010, p. 19.
} 
La figura del perro es tratada en este happening como personas imaginadas en una quimera apocalíptica. Este happening no sólo enfrenta al público a algunas de las experiencias más horrorosas sufridas por el ser humano (en gran parte en el holocausto), sino que también pretende visualizar el problema que se nos avecinaba: el superpoblamiento de la tierra. Los problemas de abastecimiento que generan y generarán, las injusticias que sobrevenían, el cambio climático, etc. son algunos de los temas aquí plasmados, por primera vez ${ }^{35}$.

De igual manera, podriamos hacer una lectura simbólica, ya que una de las concepciones en la iconografía china es aquella en la que el can sirve como medio entre los vivos y los muertos y las divinidades. Quizás el mayor aporte sea la inserción del mesianismo en la experiencia artística y que a través de las acciones vitales de estos animales se pudo llegar a una comunicación extrasensorial en el happening, pudiendo ser la primera obra de arte extrasensorial-espiritual vostelliana.

Sin llegar a ese límite, y analizando -de momento-, lo que podemos encontrar en nuestro plano, podemos afirmar que Vostell sí que pretende que realicemos un viaje espiritual a lo más profundo de nuestra psique para conectar con su mensaje, casi chamánico, sobre violencia, crueldad, satisfacción, etc. Esto mismo se sustrae de uno de sus escritos para este happe$n^{n i n g}{ }^{36}$ en el que dice "cuando realizo un happening pienso en":

"amistoso, altruista, alusivo, contradicción en la vida, casualidad, consecuencias visuales y psicológicas del entorno, comentario sobre la vida, comentario sobre los pseudo-acontecimientos, indeterminación, antropología, introspección, conciencia, autocrítica, alternancia, reflexión de los síntomas de nuestros tiempos, la fantasía y la imagen son nuestro segundo ser, la pasividad, las víctimas de situaciones de conflicto, la verdad psicológica, la rebelión de la imaginación, la heterogeneidad, nuestro entorno extienden nuestros sentimientos, las nuevas acciones tienen sus fuentes en nuevos objetos y el refinamiento de la sensibilidad".

35 Entrevista de la autora a Mercedes Guardado, en la que declara que esta obra fue la primera que habló del concepto "medio ambiente" a nivel internacional. 22.10.2015.

36 Archivo Happening Vostell. Caja número 30 (donde se hayan diferentes documentos con conceptos sobre el happening).

\section{PERRO MUERTO}

75

Este mensaje será el que nos conduzca a la segunda categoría, aquella que, aunque el perro es físicamente reconocible por el intelecto, está muerto en la exposición de la obra. Es el caso del environment recreado en El tren fluxus (1981), en el octavo vagón: Los fuegos o Mis peines son de azúcar. El tren fluxus es una obra de arte intermedia concebida "como una academia" ${ }^{37}$ que recorrió con sus nueve vagones 16 ciudades diferentes ${ }^{38}$ - Dortmund, Aquisgrán, Mülheim, Hamm, Bochum, Wuppertal, Colonia, Remscheid, Oberhausen, Essen, Düsseldorf, Münster, Leverkusen, Duisburgo, Gelsenkirchen y Bonn, permaneciendo tres días en cada una-, mostrando siete happenings instalados en vagones distintos (cada uno con un título y temática diferentes), que versaran sobre la relación del arte y la vida.

El tema de este vagón era el de "la irradiación de los elementos por la naturaleza". La imagen proyectada en este happening a través de los perros es completamente impactante. De los cuerpos de los siete animales salen cuchillos, con el filo hacia afuera ${ }^{39}$.

La insalación fue expuesta en la feria ARCO de Madrid. En esta ocasión, algunos asistentes no comprendieron. El crítico Michel Hubert describió la reacción de los asistentes de la siguiente manera:

"Recuerdo la incomprensión patética de mucha gente ante la instalación "Los fuegos" de Vostell, en ARCO de 1984, sobre todo por parte de los afiliados a la Asociación Protectora de Animales, incapaces de comprender que los puñales que asoman del cuerpo de los perros disecados son producto de la misma naturaleza que no para de matarse a sí misma, y no de la mente sádica de Vostell. Los puñales forman parte del cuerpo y brotan de ellos, como consecuencia natural de una enfermedad, con los mangos dentro y las puntas hacia afuera" ${ }^{" 40}$.

37 GUARDADO OLIVENZA, Mercedes, Mi vida con Vostell. opus cit., p. 303.

38 Ibídem, p. 301.

39 HANAS, Erin "Reconfiguring the Archive by Reconceptualizing the Ideal Academy: Wolf Vostell's". En: http:// www.journal.doc.art.pl/pdf10/art_and_text_erin_hanas.pdf, 2014, p. 10, consultado el 28-01-2019.

40 Centro de Estudios del Archivo MNCARS (Arch. M/Q 206 (5)). Documento: Sr. D. Michel Hubert Lépicouché. El impulso transgresor como motor de la obra de Vostell. Conferencia. Museo Vostell Malpartida. 1 de junio 


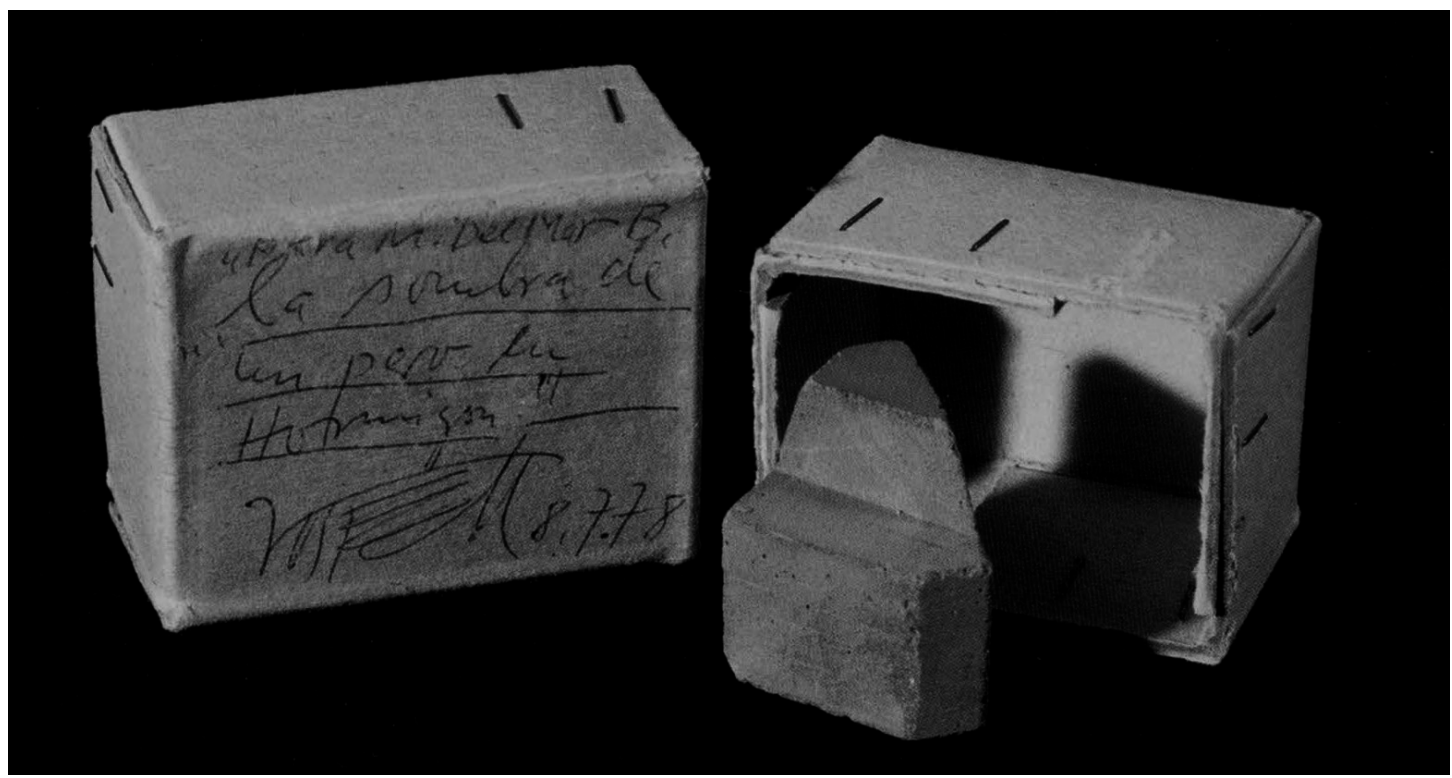

Fig. 7. La sombra de un perro de hormigón (1978). Colección privada. Cortesía coleccionistas, Archivo Happening Vostell y Junta de Extremadura.

La obra no dejaba indiferente a nadie y eso mismo es lo que había tratado de provocar Vostell. Sin embargo, el artista estuvo abierto a discutir, charlar incluso a explicar la obra de arte in situ en todo momento para que el público asistente comprendiera su mensaje. Como él mismo dijo: "la historia del arte se puede definir como una regla de vida, como la norma ética y estética más alta contra la violencia y la estupidez humana que existen paralelamente a esta historia" ${ }^{41}$.

\section{Representación abstracta:}

Llegados a este punto deberemos seguir hablando del mensaje vostelliano, pero unido al maestro indiscutible Francisco de Goya para describir la segunda categoría que nos ocupa, aquella en la que el perro no es reconocido visualmente al ser conceptualizado en la obra de arte.

La esquematización de los perros comienza en el artista hispano-germano en 1978, con su obra La sombra de un perro en hormigón, una caja de proporciones pequeñas que contiene la figura geométrica en hormigón de un

de 2001. Asociación de Amigos del Museo Vostell Malpartida.

41 Centro de Estudios del Archivo MNCARS. Documento:

El País, artículo "Arte contra violencia y estupideces humanas" (En proceso de catalogación). perro. Esta figura debe ser vista con la ayuda de una luz cenital para que proyecte una sombra, quedando completa la obra de esta manera ${ }^{42}$. Es interesante en esta creación dos aspectos fundamentales en cuanto a los canes: por un lado, nos encontramos ante una pieza relacionada con el film-happening Desastres, del que ya hemos hablado, y por lo tanto ante la reducción al mínimo de uno de los perros guardianes del Muro de Berlín ${ }^{43}$. Sin embargo -y esto nos lleva al segundo aspecto-, no podemos negar que en el aspecto plástico encuentra su referencia directa en la obra Perro semihundido de Francisco de Goya. La obra Desastres tiene el sobrenombre de Homenaje a Goya y en ella, como ya hemos dicho, aparece un perro en el espacio del Muro de Berlín, un espacio reconocible a tenor del resto de imágenes de la cinta pero individualmente confuso. Igual ocurre con la obra de Goya.

Diversos estudios hablan sobre la realidad conceptual de la creación goyesca. Por un lado,

42 VV.AA., Arte en la intimidad: Obras de Wolf Vostell En Cáceres, Ed. Consorcio Cáceres 2016, Cáceres, p. 92.

${ }^{43}$ LOZANO BARTOLOZZI, María del Mar y CORTÉS MORILLO, Josefa, "Contenedores de conceptos y de realidades: Las cajas de proyectos del Archivo Happening Vostell", Archivos y fondos documentales para el arte contemporáneo, Consejería de Cultura y Turismo de la Junta de Extremadura, Consorcio Museo Vostell Malpartida y Universidad de Extremadura. Cáceres, 2009, p. 247. 
aquellos que estudian las fotografías originales tomadas de Perro semihundido en la Quinta del Sordo ${ }^{44}$ y que describen al perro (protagonista del cuadro) en un paisaje con una roca inmerso en la observación de unos pajarillos que le sobrevuelan. Glendinning humaniza al animal dotándolo de cariño, preocupación y humil$\mathrm{dad}^{45}$, aunque Valeriano Bozal, quien aglutina en su libro todas las opiniones y posibles significaciones del cuadro, llega a la conclusión de que no es posible dar ninguna solución significativa ${ }^{46}$. La interpretación del cuadro, por tanto, queda abierta.

Wolf Vostell fue un gran conocedor de la Historia del arte, tal y como apunta Agúndez;

"Wolf Vostell es un gran conocedor de la tradición y de la gramática del arte, de su historia. ...Se reconoce deudor de la historia de arte y pretende, al tiempo que su obra es un diálogo con la sociedad, sea también un diálogo con el hombre, un diálogo con la historia" ${ }^{47}$.

$\mathrm{Al}$ artista le interesaba la capacidad de Goya para reducir al mínimo la realidad en sus imágenes pictóricas, anticipándose al resto de artistas de la historia y creando, en este cuadro, la abstracción. Así, en La sombra de un perro en hormigón realiza su versión de la obra de Goya invitando a un elemento inmaterial -como es la sombra $^{48}$ - a participar en la significación generando la misma idea que la obra parafraseada.

En 1981 el artista da un paso más allá y materializa el paisaje de La Siberia (también comentado anteriormente), su obra La sombra de un perro en hormigón y la referencia de la pintura de Goya Perro semihundido en el cuadro Siberia Extremeña (1981). Esta obra supone la suma de las tres anteriores, consiguiendo el artista reducir la escena a mínimos formales reconocibles. En ella enfrenta diferentes conceptos: "el hombre frente a la naturaleza, frente a sí mismo y frente a otros hombres" ${ }^{\prime \prime}$, la abs-

44 TORRECILLAS FERNÁNDEZ, María del Carmen, "Las pinturas de La Quinta Del Sordo fotografiadas por J. Laurent”, Boletín Del Museo Del Prado, n.13, 1992, p. 57.

45 GLENDINNING, Nigel, "La Quinta Del Sordo de Goya", Historia 16, vol. 77, n. 307, 1986, p. 108.

46 BOZAL, Valeriano, Pinturas Negras de Goya, Tf Editores, Madrid, 1997, p. 98.

47 AGÚNDEZ GARCÍA, José Antonio, 10 Happenings de Wolf Vostell, opus cit., p. 66.

48 STOICHITA, Víctor, Breve Historia de La Sombra, Ed. Siruela, Madrid, 2006.

49 VV.AA., Arte en la intimidad: Obras de Wolf Vostell en Cáceres, opus cit., p. 46. tracción del paisaje y lo desconcertante de la realidad, todos ellos discutidos y valorados de igual manera en la obra de Goya. Estamos, una vez más, ante una reinterpretación de un genio a otro genio.

\section{Conclusiones}

Como conclusión, entendemos que la presencia de los canes en la obra de Wolf Vostell no es casual, sino que es recapacitada y pretendida por el autor, dotándola de significación propia dentro de su lenguaje artístico. Podemos resumir la representación perruna en la obra vostelliana atendiendo a los siguientes criterios:

La presencia de los perros puede materializar el concepto del azar. La incursión de este animal en las obras de acción supone una ruptura con el guion preparado para cada iniciativa pues, tal y como ya hemos apuntado, es imposible predecir la actuación del animal en el desarrollo del happening. Por lo tanto, en las distintas versiones de los conciertos de Siberia Extremeña (1982), como en el concierto $E l$ Grito (1990), así como en el happening Nunca más- Jamás Jamás (1964), la aparición de un perro en el esquema compositivo de la obra supone la aceptación de que el azar, y por ende la vida misma, forme parte intrínsecamente a la acción artística.

También la presencia de los perros en la obra vostelliana puede materializar el concepto de colaboración entre los animales y los seres humanos, principalmente, en las obras en las que el artista interactúa con el animal. De las distintas experiencias de los conciertos podemos observar cómo el trabajo conjunto entre el hombre y los perros nos retrotrae a otras experiencias laborales pasadas que nos conectan, de manera directa, con nuestras raíces. La ganadería, el pastoreo o la trashumancia son actividades en las que el hombre trabaja mano a pata con los animales, apoyándose el uno en el otro y generando un lazo de unión entre los dos irrompible. De esta manera subraya Wolf Vostell la necesidad de retornar al pasado, a las raíces culturales en las que, desde hace miles de años, el hombre ha sido hombre y el perro su más fiel compañero.

Del mismo modo, la inclusión de los perros en las obras de arte de Vostell, como las distintas versiones de Depresión Endógena (1978 y 


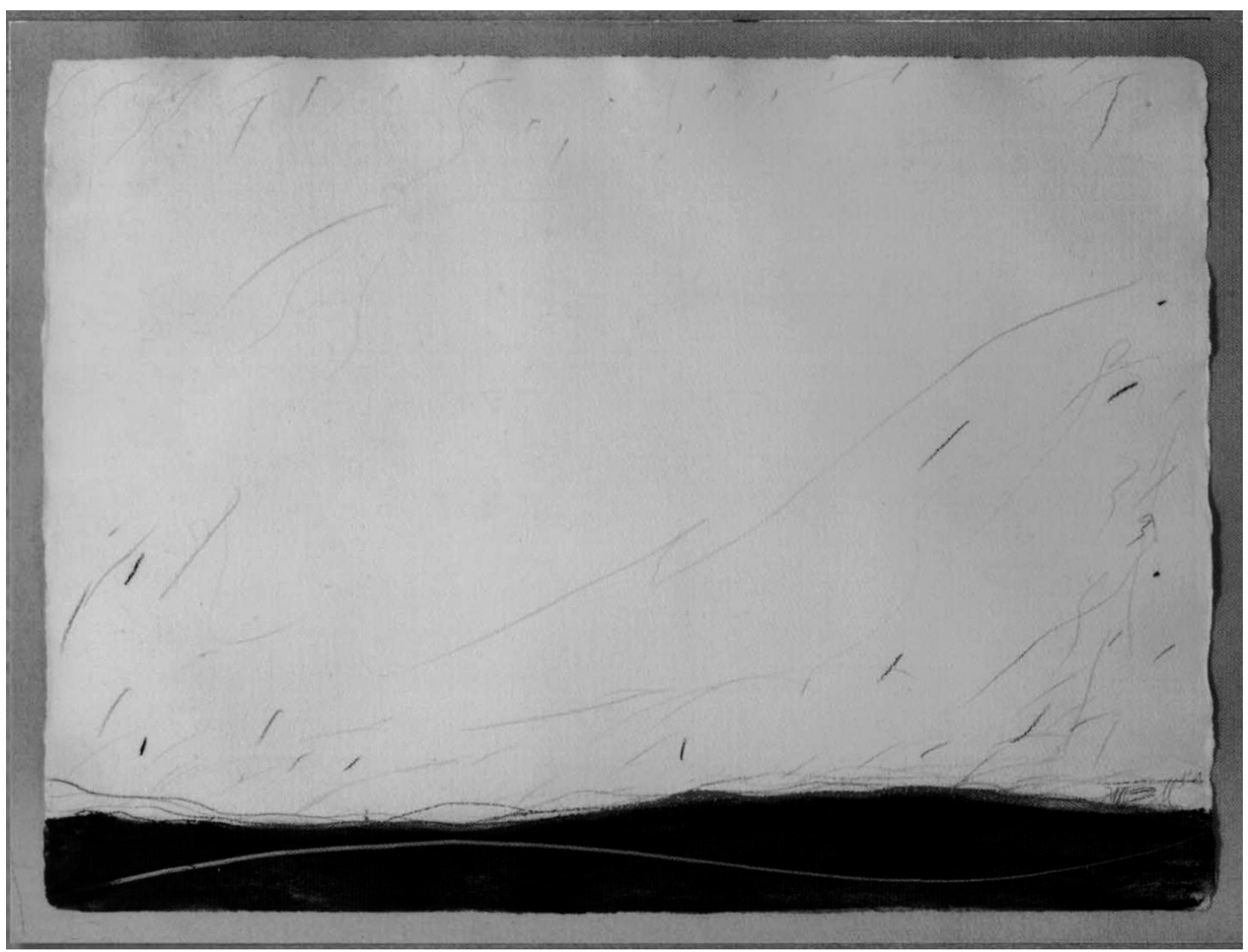

Fig. 8. Siberia extremeña (1981). Colección privada. Cortesía coleccionistas, Archivo Happening Vostell y Junta de Extremadura.

1979), materializan los opuestos entre tecnología y naturaleza, ya que encontramos cómo los dispositivos electrónicos hormigonados presentes se exponen como cadáveres anquilosados de una cultura que consume y desecha cada vez más rápido. Sin embargo, los seres vivos son los que siguen habitando y llenando de vida el espacio, pudiendo realizar las acciones que su instinto dispone para ellos. La vida natural se impone a la vida tecnológica y el perro será, en este caso, el guardián del transcurrir de los flujos vitales, quien nos muestre las capacidades sensitivas innatas a los seres vivos

Igualmente, la presencia de los canes puede personificar al hombre y su historia más reciente, como en los happenings Perros y Chinos no son admitidos (1966) o Desastres (1972), donde, una vez más, el artista expone las atrocidades llevadas a cabo por el ser humano. En una, encierra y muestra a los perros el transcurrir de las actividades del happening, prohibiéndoles la participación en el desarrollo del guion pro- puesto por Vostell, tal y como el gobierno inglés hizo con el pueblo chino (hecho del que deriva el título de esta obra). Del mismo modo utiliza el artista a los canes en el happening Desastres, donde expone la visión de estos animales como presencia de la vigilancia y control que unos seres humanos ejercieron sobre otros en la desgarradora existencia del Muro de Berlín.

De manera extraordinaria, el azar, la colaboración, las antiguas y nuevas tecnologías, las capacidades intrínsecas a los organismos y el peso de la historia del hombre, personifican el dogma vostelliano arte $=v i d a$, vida $=$ arte. $\mathrm{Y}$ es especialmente interesante cómo en todos ellos la figura del perro está presente, bien sugerido, bien presencialmente, pero en todas y cada una de ellas el perro expresa verdades inherentes al alma de Wolf Vostell. Tal y como el artista expresó "el arte que no enseña, no es arte", y Vostell pretendió, a través de las figuras de los canes y del arte, darnos a conocer alguna de las verdades más intensas de la vida. 